\title{
Re-assessing the role of water-column sulphide formation in the marine $\mathrm{Cd}$ cycle
}

\author{
GREGORY DE SOUZA ${ }^{1}$, DEREK VANCE ${ }^{2}$, MATTHIAS \\ SIEBER $^{3}$, TIM CONWAY ${ }^{3}$ AND SUSAN H LITTLE ${ }^{4}$ \\ ${ }^{1}$ ETH Zurich \\ ${ }^{2}$ ETH Zürich \\ ${ }^{3}$ University of South Florida \\ ${ }^{4}$ University College London \\ Presenting Author: desouza@erdw.ethz.ch
}

It has been inferred that the marine distributions of the micronutrient cadmium $(\mathrm{Cd})$ and its stable isotope composition (expressed as $\delta^{114} \mathrm{Cd}$ ) bear widespread and unambiguous evidence for loss of $\mathrm{Cd}$ from the water column through the formation of solid cadmium sulphide (CdS) in oxygen minimum zones (OMZs) [1]. Recent research has suggested that this watercolumn $\mathrm{CdS}$ formation may represent the largest $\mathrm{Cd}$ sink term in its whole-ocean budget [2]. Here, by bringing together previously-published elemental and isotopic datasets from the dissolved and particulate $\mathrm{Cd}$ pools, we unravel the multiple, overlapping controls on the $\mathrm{Cd}$ and $\delta^{114} \mathrm{Cd}$ distributions, demonstrating that the data challenge this view.

Our analysis reveals that the most important control on the marine $\mathrm{Cd}$ distribution is the extreme plasticity in the cadmium:phosphorus (Cd:P) stoichiometry of biological uptake, and thus particulate export. We show that the $\delta^{114} \mathrm{Cd}$ systematics in low-latitude OMZs that have been taken to reflect Cd loss in fact mainly come about through interaction between the physical circulation and the stoichiometric plasticity of biological $\mathrm{Cd}$ uptake at high and low latitudes. Water-column evidence for $\mathrm{Cd}$ loss is thus much less widespread than has previously been inferred.

Subtle but consistent signals in particulate elemental and dissolved isotopic data from the tropical Atlantic and Pacific Oceans do allow us to identify the signal of a Cd loss associated with the oxycline of the shallow tropical subsurface, as has previously been suggested [e.g. 1-5]. However, this Cd loss appears to be ubiquitous throughout the tropics, rather than confined to oxygen-poor waters, speaking against $\mathrm{CdS}$ formation as the driving mechanism. Although its true identity remains unknown, this tropical $\mathrm{Cd}$ loss may be related to biological activity. Most generally, our analysis bears upon the contribution of water-column $\mathrm{CdS}$ formation to the whole-ocean mass balance of $\mathrm{Cd}$, which is likely to be much smaller than recent estimates have suggested.

[1] Janssen et al. (2014) PNAS 111, doi: 10.1073/ pnas.1402388111 [2] Guinoiseau et al. (2019) GBC 33, doi: 10.1029/2019GB006323 [3] Conway \& John (2015) GCA 148, 269-283 [4] Xie et al. (2019) Chem. Geol. 511, 371-379 [5] Ohnemus et al. (2019) 33, doi: 10.1029/2018GB006145. 